\title{
A Differential-Algebraic Model for the Once-Through Steam Generator of MHTGR-Based Multimodular Nuclear Plants
}

\author{
Zhe Dong $^{1,2}$ \\ ${ }^{1}$ Institute of Nuclear and New Energy Technology, Tsinghua University, Beijing 100084, China \\ ${ }^{2}$ Key Laboratory of Advanced Reactor Engineering and Safety, Ministry of Education of China, Beijing 100084, China
}

Correspondence should be addressed to Zhe Dong; dongzhe@mail.tsinghua.edu.cn

Received 4 April 2014; Accepted 4 August 2014

Academic Editor: Zhijun Zhang

Copyright (C) 2015 Zhe Dong. This is an open access article distributed under the Creative Commons Attribution License, which permits unrestricted use, distribution, and reproduction in any medium, provided the original work is properly cited.

\begin{abstract}
Small modular reactors (SMRs) are those fission reactors whose electrical output power is no more than $300 \mathrm{MW}_{\mathrm{e}}$. SMRs usually have the inherent safety feature that can be applicable to power plants of any desired power rating by applying the multimodular operation scheme. Due to its strong inherent safety feature, the modular high temperature gas-cooled reactor (MHTGR), which uses helium as coolant and graphite as moderator and structural material, is a typical SMR for building the next generation of nuclear plants (NGNPs). The once-through steam generator (OTSG) is the basis of realizing the multimodular scheme, and modeling of the OTSG is meaningful to study the dynamic behavior of the multimodular plants and to design the operation and control strategy. In this paper, based upon the conservation laws of mass, energy, and momentum, a new differential-algebraic model for the OTSGs of the MHTGR-based multimodular nuclear plants is given. This newly-built model can describe the dynamic behavior of the OTSG in both the cases of providing superheated steam and generating saturated steam. Numerical simulation results show the feasibility and satisfactory performance of this model. Moreover, this model has been applied to develop the real-time simulation software for the operation and regulation features of the world first underconstructed MHTGR-based commercial nuclear plant-HTR-PM.
\end{abstract}

\section{Introduction}

Nuclear fission energy is a crucial type of clean energy sources that can meet the world's increasing energy demands and also address challenges associated with global climate and environmental impact. After the successful development of small (tens of megawatts) light water reactors (LWRs) for propulsion by the U.S. Navy, the commercial fission reactors began to commission in the late 1950s and early 1960s, which were essentially the scaled-up versions of those naval nuclear reactors [1]. As plant sizes grew and as operational issues began to moderate the industry's confidence in the plant safety, more stringent safety requirements were imposed, which induced a complex layering of redundant safety and auxiliary systems to the original simple LWRs. This escalation of plant complexity contributed to rapidly increasing costs, licensing periods, and construction delays. However, these complicated safety equipment still cannot well guarantee the plant safety. After the severe nuclear accidents, that is, the Three Mile Island, Chernobyl, and Fukushima, the safety issues of nuclear reactors have become much more significant than before. Small modular reactors (SMRs) are those nuclear fission reactors whose electrical output power is less than $300 \mathrm{MW}_{\mathrm{e}}$. Due to the low power density and large heat capacity, SMRs usually have the inherent safety feature, and could be beneficial in providing electricity power to remote areas without transmission or distribution infrastructure, in generating local power for a large population center and in being viable for specific applications such as heat sources for the industrial complexes [2]. SMRs with load following function can be incorporated with new energy sources such as the solar and wind to build microgrids that have the virtues of persistent power supply, free refueling of nuclear fission fuels, and capability of seawater desalination and heat production. Moreover, by adopting multimodular operation strategy, that is, multi-SMRs providing steam for one turbine/generator set, the inherent safety feature can then be applicable to large power plants of any desired power ratings. Relative to the conventional nuclear plant, the most advanced feature of the SMR-based plants is the inherent safety feature which 


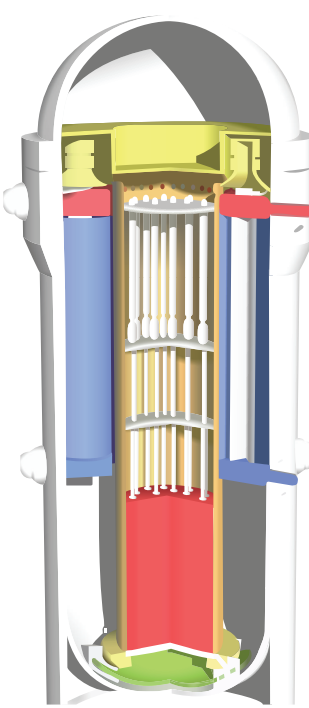

(a) IRIS

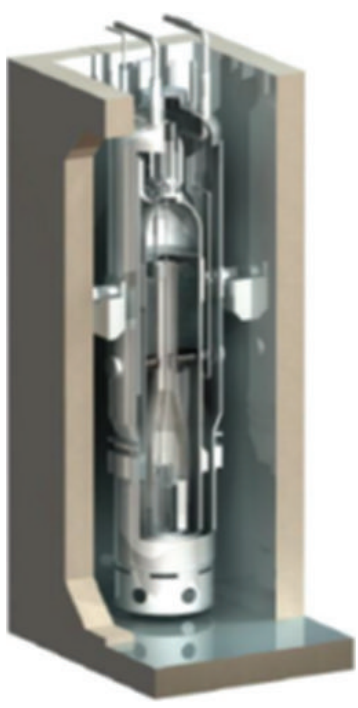

(b) NuScale

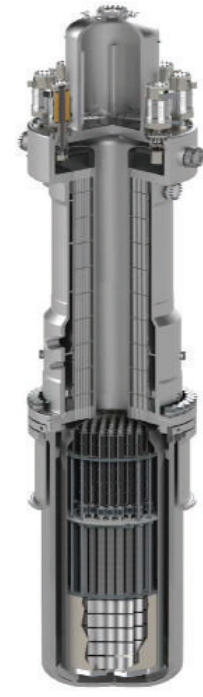

(c) mPower

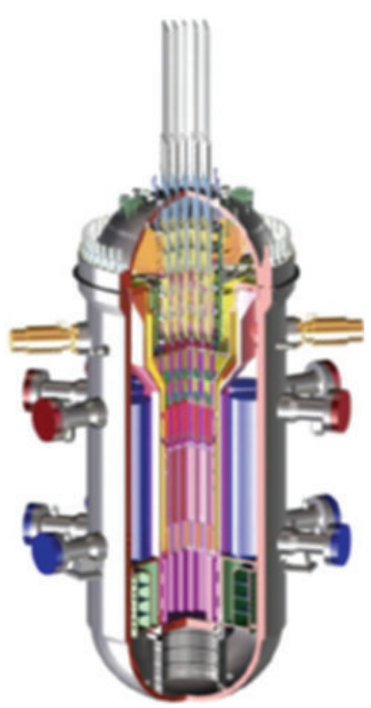

(d) SMART

FIGURE 1: Schematic views of some LWR-type SMRs.

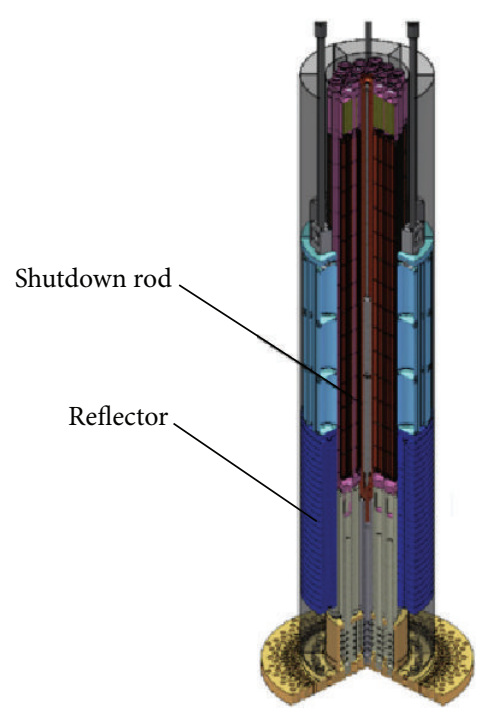

(a) Reactor

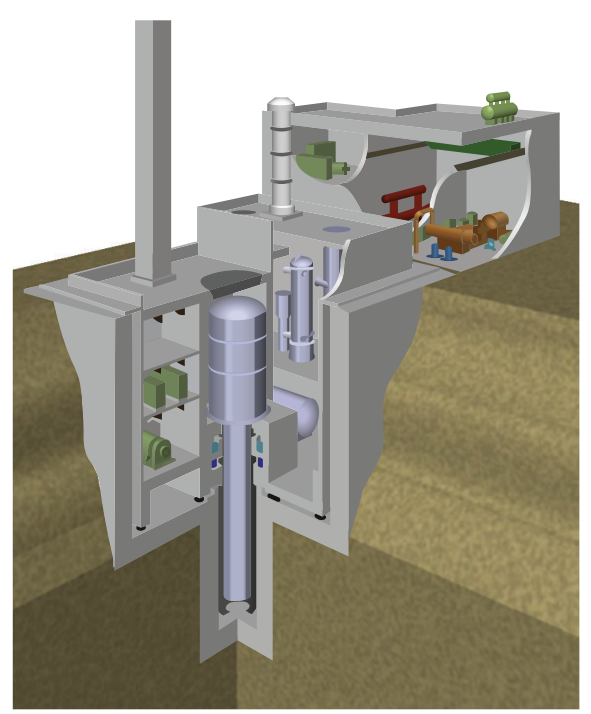

(b) Plant structure

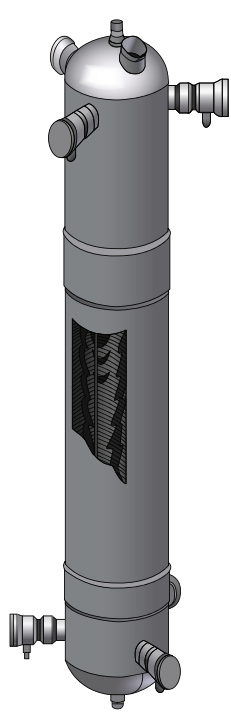

(c) OTSG

FIGURE 2: 4S nuclear energy system.

prevents SMRs from the hazards of core-melting, radiological release, and LOCA (Loss of Coolant Accident). Furthermore, SMRs can offer simpler, safer, and standardized modular design by being factory built, requiring smaller initial capital investment, and having shorter construction period, and have been viewed by International Atomic Energy Agency (IAEA) as one of the active developing trends of nuclear energy.

There are three major groups of SMR designs that are actively being developed in the US, China, Japan, Korea, and other countries. As shown in Figure 1, the first group of SMRs is based on the design concepts of proven and widely used light water reactors (LWRs) such as the IRIS (international reactor innovative and secure), NuScale and mPower designed by US, and the SMART designed by Korea. These
SMRs usually have the safety features of strong naturalcirculation and self-pressurized and are usually tightly coupled with the once-through steam generators (OTSGs) to provide superheated steam $[3,4]$. The second group are those SMRs cooled either by liquid metal or liquid salt such as the $4 \mathrm{~S}$ (Super-Safe, Small and Simple) fast reactor designed by Toshiba, fueled with enriched uranium or plutonium and cooled by sodium. The schematic view of the $4 \mathrm{~S}$ nuclear energy system is shown in Figure 2 from which we can see that the OTSG is also utilized here for providing super-heated steam [4]. The third group consists of gas-cooled SMRs. The modular high temperature gas-cooled reactor (MHTGR), which uses helium as coolant and graphite as both moderator and structural materials, is a crucial 


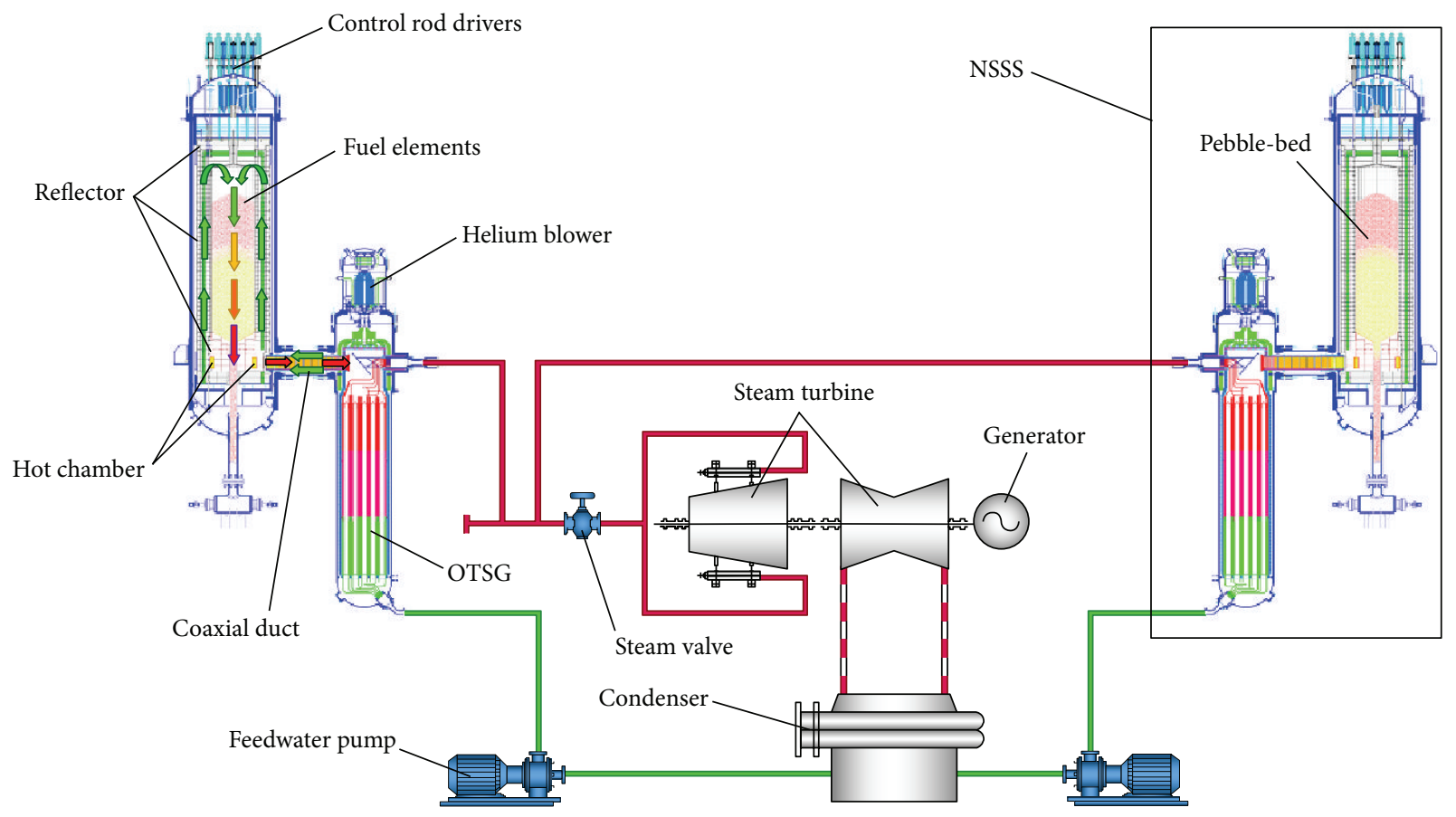

FIGURE 3: Structure of the HTR-PM plant.

gas-cooled SMR and has been seen as one the best candidates for building the next generation of nuclear plant (NGNP). The inherent safety feature of the MHTGR is given by its low power density, strong negative temperature feedback effect, and slim reactor shape [5]. The first MHTGR of China, that is, $10 \mathrm{MW}_{\text {th }}$ pebble-bed high temperature gas-cooled reactor HTR-10, which was developed by the institute of nuclear and new energy technology (INET) of Tsinghua University, achieved its full power-level in 2003 [6]. Based upon HTR-10, the high temperature gas-cooled reactor pebble-bed module (HTR-PM) plant has already been designed by INET and is now under construction. From Figure 3, HTR-PM is a twomodular nuclear plant that is the first MHTGR-based underconstructed commercial plant. Each module of HTR-PM is a nuclear steam supply system (NSSS) constituted by a pebblebed one-zone MHTGR, a side-by-side arranged helical-coil OTSG and some connecting pipes [7,8]. Similar to the first and second groups of SMRs, the outlet steam of HTR-PM's NSSS is also superheated.

From the above introduction, it is clear to see that the OTSG is key equipment in the SMR-based nuclear energy systems. Actually, this is given by the necessity of building large nuclear plants based on parallel-operated multi-SMRs. The precondition of applying this parallel operation scheme is that the pressure of the steam generated by each NSSS must be equal to each other. Since the widely-utilized U-tube steam generators (UTSG) can only provide saturated steam whose pressure and temperature must obey the one-to-one relationship, parallel-operating SMRs based on the UTSGs may lead to the drift in the steady values of the coolant temperatures [9]. Since the OTSG can provide superheated steam which does not satisfy the one-to-one map from pressure to temperature, the OTSG is more proper for building multiSMR based nuclear plants [10]. Therefore, it is clear that the dynamic model of the OTSG is very crucial for studying behavior of the SMR-based plant and also for verifying the operation and control strategies. Up to now, there have already been some works in building the dynamic models of OTSGs. Through dividing the OTSG secondary side into the subcooled, evaporating, and superheated sections, Ray gave a nonlinear dynamic model to the OTSG of a solar plant $[11,12]$. By further dividing the aforementioned evaporating section into the two regions of nucleate boiling and film boiling, Tzanos and Abdalla independently proposed the four region moving boundary models for the helical-coil OTSGs of the advanced liquid metal reactor (ALMR) $[13,14]$. Recently, Li et al. gave a three-region dynamic model for the OTSG of the HTR-10 plant [15].

The above OTSG models are all developed under the assumption that the outlet steam is superheated. However, in some actual cases such as the plant startup or operation in very low power, the OTSG might also generate saturated steam. The OTSG dynamics in these cases is quite significant for designing the plant operation strategy, but it cannot be described by the models presented in [11-15]. Therefore, it is very necessary to give OTSG models for describing the dynamic behavior in the cases of generating saturated steam. In this paper, a moving boundary region dynamic model of the OTSG of the MHTGR-based multimodular nuclear plant is proposed. This model can be used to describe the OTSG dynamics in the cases of providing superheated steam and generating saturated steam. Then, numerical simulation results show the feasibility of this new model. This model has already been adopted to develop the real-time simulation 


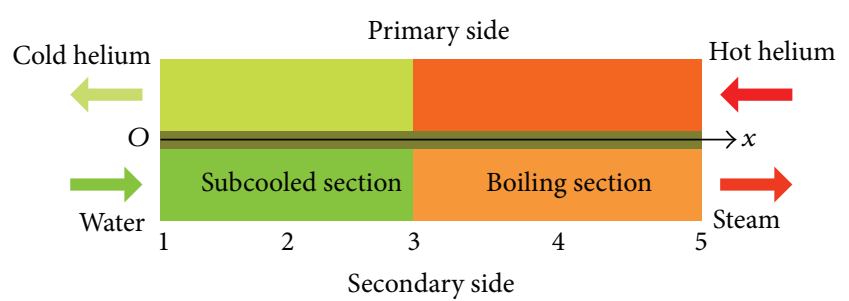

FIGURE 4: Nodalization scheme of the OTSG.

software for the operation and control characteristics of HTRPM plant. Moreover, the approach of building this new model can be applied to give the dynamic models for the OTSGs of other SMR-based multimodular nuclear plants.

\section{Modeling Principles}

The OTSG of MHTGR-based multimodular nuclear plants such as the HTR-PM is a helical-coil once-through shelland-tube counterflow heat exchanger. The hot helium flows into the primary shell side, and the cold water is fed into the secondary tube side. The hot helium transfers the thermal power from the primary side to the secondary water/steam two phase flow, which results in cooling the helium and heating the feedwater to superheated or saturated steam. Here, it is assumed that the two phase flows in all the tubes of the OTSG are identical, which means that the OTSG can be simply treated as a single tube heat exchanger. In order to obtain dynamic model that is suitable to not only the case of providing superheated steam but also the case of generating saturated steam, the OTSG is divided into two sections, that is, the subcooled section and boiling section. This nodalization scheme is illustrated in Figure 4, and the boundary between these two sections is assumed to be movable. Here, define $l_{i j}(i, j=1, \ldots, 5$ and $i<j)$ as the length between nodes $i$ and $j$ in Figure 4 .

Then, under the coordinate frame given in Figure 4 and based on the conservation laws of mass, energy, and momentum at position $x$ in the flow channel at time $t$, we have

$$
\begin{aligned}
\frac{\partial \rho}{\partial t}+\frac{\partial D}{\partial x} & =0 \\
\frac{\partial(\rho h)}{\partial t}+\frac{\partial(D h)}{\partial x} & =\frac{q}{A}+\frac{\partial P}{\partial t}, \\
\frac{\partial D}{\partial t}+\frac{\partial}{\partial x}\left(\frac{D^{2}}{\rho}\right)+\frac{\partial P}{\partial x} & =-\frac{1}{2} \frac{D^{2}}{\rho} \frac{S}{A} f_{f}-\rho g,
\end{aligned}
$$

where $\rho$ is the fluid density $\left(\mathrm{kg} / \mathrm{m}^{3}\right), D$ is the fluid mass velocity $\left(\mathrm{kg} /\left(\mathrm{s} \cdot \mathrm{m}^{2}\right)\right), h$ is the fluid enthalpy per unit mass $(\mathrm{J} / \mathrm{kg}), q$ is the heat flux per unit length, $P$ is the fluid pressure $(\mathrm{Pa}), f_{f}$ is the fanning friction factor, $S$ is the flow channel wetted perimeter $(\mathrm{m}), A$ is the area of the flow cross-section $\left(\mathrm{m}^{2}\right)$, and $g$ is the gravitational acceleration $\left(\mathrm{N} \cdot \mathrm{m} / \mathrm{s}^{2}\right)$. The OTSG dynamic model in this paper is obtained based upon the conservation laws determined by (1)-(3).
Moreover, to obtain the lumped parameter model of the OTSG based on integrating (1)-(3) along the direction of $x$-axis defined in Figure 4, the following useful lemma is introduced here.

Lemma 1 (Leibnitz). For a continuously differentiable function $\alpha(t), \beta(t)$, and $\gamma(z, t)$, equation

$$
\begin{aligned}
\frac{d}{d t} \int_{\alpha(t)}^{\beta(t)} \gamma(z, t) d z \\
=\int_{\alpha(t)}^{\beta(t)} \frac{\partial \gamma(z, t)}{\partial t} d z+\gamma(\beta(t), t) \frac{d \beta(t)}{d t} \\
\quad-\gamma(\alpha(t), t) \frac{d \alpha(t)}{d t}
\end{aligned}
$$

can be well-satisfied, where $z, t \in R$.

\section{Nonlinear Differential-Algebraic Model}

Based upon conservation laws (1)-(3) and Lemma 1, the dynamic model of OTSG is developed in the following parts of this section.

3.1. Dynamic Equations of the Secondary Side. The dynamic equations of both the subcooled and boiling sections of the OTSG secondary side are established in this subsection.

3.1.1. Subcooled Section. In the subcooled section, integrate (1) and (2) along the direction of $x$-axis defined in Figure 4, and we have

$$
\begin{gathered}
\frac{d\left(\rho_{s 2} l_{13}\right)}{d t}-\rho_{s 3} \frac{d l_{13}}{d t}+D_{3}-D_{1}=0, \\
\frac{d\left(\rho_{s 2} h_{s 2} l_{13}\right)}{d t}-\rho_{s 3} h_{s 3} \frac{d l_{13}}{d t}+D_{s 3} h_{s 3}-D_{s 1} h_{s 1} \\
=\frac{Q_{s 2}}{A_{2}}+\frac{d\left(P_{s 2} l_{13}\right)}{d t}-P_{s 3} \frac{d l_{13}}{d t},
\end{gathered}
$$

where $Q_{s 2}$ and $Q_{s 2}$ are the heat flux from the tube-wall to the flow of the secondary side in the subcooled and boiling sections, respectively.

Moreover, since the dynamic behavior of the pressureflow process is much faster than that of the enthalpytemperature process, the time-differentiation term in (3) can be omitted here; that is, we can suppose that

$$
\frac{\partial}{\partial x}\left(\frac{D^{2}}{\rho}\right)+\frac{\partial P}{\partial x}=-\frac{1}{2} \frac{D^{2}}{\rho} \frac{S}{A} f_{f}-\rho g .
$$

Then, by integrating (7) along $x$-axis in the subcooled section, we have

$$
P_{s 3}=P_{s 1}-\rho_{s 2} g l_{13} \sin \theta-F_{s 2} l_{13} D_{s 2}^{2},
$$

where $\theta$ is the helically coiled angle of the tubes and $F$ is the friction factor of pressure. 
Since the water near point 3 in Figure 4 is saturate, from the thermodynamic features of saturate water, we can derive that

$$
\frac{d h_{s 3}}{d t}=\left.\frac{\partial h_{s 3}}{\partial P_{s 3}}\right|_{P_{s 3}} \frac{d P_{s 3}}{d t} .
$$

Moreover, it is not loss generality to assume that

$$
\begin{gathered}
G_{s 2}=D_{s 2} A_{s 2}, \\
G_{s 2}=\frac{G_{s 1}+G_{s 3}}{2}, \\
h_{s 2}=\frac{h_{s 1}+h_{s 3}}{2}, \\
P_{s 2}=\frac{P_{s 1}+P_{s 3}}{2},
\end{gathered}
$$

where $G_{s}$ is the flowrate of the secondary side.

Based on (8)-(10) and by subtracting the multiplication of (5) and $h_{2}$ from (6), we have

$$
\begin{aligned}
& \frac{1}{2}\left[\rho_{s 3}\left(h_{s 1}-h_{s 3}\right)+\left(P_{s 3}-P_{s 1}\right)\right. \\
& \left.+l_{13}\left(1-\left.\rho_{s 2} \frac{\partial h_{s 3}}{\partial P_{s 3}}\right|_{P_{s 3}}\right)\left(\rho_{s 2} g \sin \theta+F_{s 2} \frac{G_{s 2}^{2}}{A_{s 2}^{2}}\right)\right] \frac{d l_{13}}{d t} \\
& \quad+\frac{1}{2} \rho_{s 2} l_{13} \frac{d h_{s 1}}{d t}+\frac{F_{s 2} G_{s 2}^{2} l_{13}^{2}}{2 A_{s 2}^{2}}\left(1-\left.\rho_{s 2} \frac{\partial h_{s 3}}{\partial P_{s 3}}\right|_{P_{s 3}}\right) \frac{d G_{s 3}}{d t} \\
& =\frac{Q_{s 2}}{A_{s 2}}+\frac{1}{2}\left(\frac{G_{s 1}}{A_{s 1}}+\frac{G_{s 3}}{A_{s 3}}\right)\left(h_{s 1}-h_{s 3}\right) .
\end{aligned}
$$

By considering the transport inertia in the subcooled section, the dynamics of the secondary-side flowrate and water enthalpy at point 1 can be described by

$$
\begin{aligned}
& \frac{d G_{s 3}}{d t}=\frac{G_{s 1}-G_{s 3}}{\tau_{G}}, \\
& \frac{d h_{s 1}}{d t}=\frac{h_{f w}-h_{s 1}}{\tau_{H}},
\end{aligned}
$$

respectively, where both $\tau_{G}$ and $\tau_{H}$ are given positive constants.

3.1.2. Boiling Section. Due to the high velocity and relative low density of the fluid in the boiling section, we assume that

$$
G_{s 3}=G_{s 4}=G_{s 5},
$$

and further we also suppose that

$$
\begin{aligned}
& h_{s 4}=\frac{h_{s 3}+h_{s 5}}{2}, \\
& P_{s 4}=\frac{P_{s 3}+P_{s 5}}{2} .
\end{aligned}
$$

From Lemma 1 and by integrating (1), (2), and (7) along the direction of $x$-axis in the boiling section, we can obtain that

$$
\begin{gathered}
\frac{d\left(\rho_{s 4} l_{35}\right)}{d t}+\rho_{s 3} \frac{d l_{13}}{d t}+D_{s 5}-D_{s 3}=0, \\
\frac{d\left(\rho_{s 4} h_{s 4} l_{35}\right)}{d t}+\rho_{s 3} h_{s 3} \frac{d l_{13}}{d t}+D_{s 5} h_{s 5}-D_{s 3} h_{s 3} \\
=\frac{Q_{s 4}}{A_{s 4}}+\frac{d\left(P_{s 4} l_{35}\right)}{d t}+P_{s 3} \frac{d l_{13}}{d t}, \\
P_{s 5}=P_{s 3}-\rho_{s 4} g l_{35} \sin \theta-F_{s 4} l_{35} D_{s 4}^{2} .
\end{gathered}
$$

Based upon relationship between (14)-(15) and (18) and by subtracting the multiplication of (16) and $h_{4}$ from (17), we have

$$
\begin{aligned}
& \frac{1}{2} \rho_{s 4} l_{35} \frac{d h_{s 5}}{d t} \\
& +\frac{1}{2}\left\{\rho_{s 3}\left(h_{s 3}-h_{s 5}\right)+\left(P_{s 5}-P_{s 3}\right)\right. \\
& +l_{35}\left[\left(2-\left.\rho_{s 4} \frac{\partial h_{s 3}}{\partial P_{s 3}}\right|_{P_{s 3}}\right)\left(\rho_{s 2} g \sin \theta+F_{s 2} \frac{G_{s 2}^{2}}{A_{s 2}^{2}}\right)\right. \\
& +l_{35}\left[\left(1-\left.\frac{1}{2} \rho_{s 4} \frac{\partial h_{s 3}}{\partial P_{s 3}}\right|_{P_{s 3}}\right) \frac{F_{s 2} G_{s 2} l_{13}}{A_{s 2}^{2}}\right. \\
& \left.+\frac{2 F_{s 4} G_{s 4} l_{13}}{A_{s 2}^{2}}\right] \frac{d G_{s 3}}{d t} \\
& =\frac{Q_{s 4}}{G_{s 4}\left(h_{s 3}-h_{s 5}\right)} \\
& A_{s 4}
\end{aligned}
$$

3.1.3. State-Space Model of the Secondary Side. Define the state-vector and input-vector of the OTSG secondary side as

$$
\begin{gathered}
\mathbf{x}_{s}=\left[\begin{array}{llll}
l_{13} & h_{s 5} & h_{s 1} & G_{s 3}
\end{array}\right]^{T}, \\
\mathbf{u}_{s}=\left[\begin{array}{llll}
G_{s 1} & h_{f w} & Q_{s 2} & Q_{s 4}
\end{array}\right]^{T},
\end{gathered}
$$

respectively.

Then, based upon (11), (19), (13), and (12), the nonlinear state-space model of the secondary side can be written as

$$
\mathbf{E}_{s}\left(\mathbf{x}_{s}\right) \dot{\mathbf{x}}_{s}=\mathbf{f}_{s}\left(\mathbf{x}_{s}, \mathbf{u}_{s}\right)
$$


where

$$
\begin{aligned}
& \mathbf{E}_{s}\left(\mathbf{x}_{s}\right)=\left[\begin{array}{cccc}
E_{s 11}\left(\mathbf{x}_{s}\right) & 0 & \frac{1}{2} \rho_{s 2} l_{13} & E_{s 14}\left(\mathbf{x}_{s}\right) \\
E_{s 21}\left(\mathbf{x}_{s}\right) & \frac{1}{2} \rho_{s 4} l_{35} & 0 & E_{s 24}\left(\mathbf{x}_{s}\right) \\
0 & 0 & \tau_{H} & 0 \\
0 & 0 & 0 & \tau_{G}
\end{array}\right], \\
& E_{s 11}\left(\mathbf{x}_{s}\right)=\frac{1}{2}\left[\rho_{s 3}\left(h_{s 1}-h_{s 3}\right)+\left(P_{s 3}-P_{s 1}\right)\right. \\
& +l_{13}\left(1-\left.\rho_{s 2} \frac{\partial h_{s 3}}{\partial P_{s 3}}\right|_{P_{s 3}}\right) \\
& \left.\times\left(\rho_{s 2} g \sin \theta+F_{s 2} \frac{G_{s 2}^{2}}{A_{s 2}^{2}}\right)\right], \\
& E_{s 14}\left(\mathbf{x}_{s}\right)=\frac{F_{s 2} G_{s 2}^{2} l_{13}^{2}}{2 A_{s 2}^{2}}\left(1-\left.\rho_{s 2} \frac{\partial h_{s 3}}{\partial P_{s 3}}\right|_{P_{s 3}}\right) \text {, } \\
& E_{s 21}\left(\mathbf{x}_{s}\right)=\frac{1}{2}\left\{\rho_{s 3}\left(h_{s 3}-h_{s 5}\right)+\left(P_{s 5}-P_{s 3}\right)\right. \\
& +l_{35}\left[\left(2-\left.\rho_{s 4} \frac{\partial h_{s 3}}{\partial P_{s 3}}\right|_{P_{s 3}}\right)\right. \\
& \times\left(\rho_{s 2} g \sin \theta+F_{s 2} \frac{G_{s 2}^{2}}{A_{s 2}^{2}}\right) \\
& \left.\left.-\left(\rho_{s 4} g \sin \theta+F_{s 4} \frac{G_{s 4}^{2}}{A_{s 4}^{2}}\right)\right]\right\} \text {, } \\
& E_{s 24}\left(\mathbf{x}_{s}\right) \\
& =l_{35}\left[\left(1-\left.\frac{1}{2} \rho_{s 4} \frac{\partial h_{s 3}}{\partial P_{s 3}}\right|_{P_{s 3}}\right) \frac{F_{s 2} G_{s 2} l_{13}}{A_{s 2}^{2}}+\frac{2 F_{s 4} G_{s 4} l_{13}}{A_{s 2}^{2}}\right], \\
& \mathbf{f}_{s}\left(\mathbf{x}_{s}, \mathbf{u}_{s}\right)=\left[\begin{array}{c}
\frac{Q_{s 2}}{A_{s 2}}+\frac{1}{2}\left(\frac{G_{s 1}}{A_{s 1}}+\frac{G_{s 3}}{A_{s 3}}\right)\left(h_{s 1}-h_{s 3}\right) \\
\frac{Q_{s 4}+G_{s 4}\left(h_{s 3}-h_{s 5}\right)}{A_{s 4}} \\
\frac{h_{f w}-h_{s 1}}{\tau_{H}} \\
\frac{G_{s 1}-G_{s 3}}{\tau_{G}}
\end{array}\right] \text {. }
\end{aligned}
$$

3.2. Differential Equations of the Tube-Wall. Since there is no flow inside the metal tube wall between the primary and secondary sides, it is clear that partial differential equation (2) describing the energy conservation law can be simplified as

$$
\frac{\partial(\rho h)}{\partial t}=\frac{q}{A} .
$$

Here, for the simplicity of the model, we assume that the tube temperature is linearly distributed along $x$-axis defined in Figure 4. Then, by integrating (24) along $x$-axis and by using Lemma 1, we have

$$
\begin{aligned}
& \rho_{m} C_{m} \frac{d}{d t}\left(l_{13} T_{m 2}\right)=\frac{Q_{p 2}-Q_{s 2}}{A_{m 2}}+\rho_{m} C_{m} T_{m 3} \frac{d l_{13}}{d t}, \\
& \rho_{m} C_{m} \frac{d}{d t}\left(l_{35} T_{m 4}\right)=\frac{Q_{p 4}-Q_{s 4}}{A_{m 4}}-\rho_{m} C_{m} T_{m 3} \frac{d l_{13}}{d t},
\end{aligned}
$$

where

$$
T_{m 3}=\frac{l_{35} T_{m 2}+l_{13} T_{m 4}}{l_{15}},
$$

and $Q_{p 2}$ and $Q_{p 4}$ are, respectively, the heat flux from the primary helium flow to tube-wall in the subcooled and boiling sections.

From (25) and (26), we can further obtain the dynamic equations of the tube-wall between the primary and secondary sides as

$$
\begin{aligned}
& \frac{d T_{m 2}}{d t}=\frac{Q_{p 2}-Q_{s 2}}{C_{m} \rho_{m} A_{m 2} l_{13}}+\frac{T_{m 4}-T_{m 2}}{l_{15}} \frac{d l_{13}}{d t}, \\
& \frac{d T_{m 4}}{d t}=\frac{Q_{p 4}-Q_{s 4}}{C_{m} \rho_{m} A_{m 4} l_{35}}+\frac{T_{m 4}-T_{m 2}}{l_{15}} \frac{d l_{13}}{d t} .
\end{aligned}
$$

By defining

$$
\begin{gathered}
\mathbf{x}_{m}=\left[\begin{array}{ll}
T_{m 2} & T_{m 4}
\end{array}\right]^{T}, \\
\mathbf{u}_{m}=\left[\begin{array}{ll}
Q_{p 2}-Q_{s 2} & Q_{p 4}-Q_{s 4}
\end{array}\right]^{T},
\end{gathered}
$$

the state-space model of the tube wall can be written as

$$
\dot{\mathbf{x}}_{m}=\mathbf{A}_{m}(\dot{\mathbf{x}}) \mathbf{x}_{m}+\mathbf{B}_{m}(\mathbf{x}) \mathbf{u}_{m}
$$

where

$$
\begin{gathered}
\mathbf{A}_{m}(\dot{\mathbf{x}})=\frac{\dot{l}_{13}}{l_{15}}\left[\begin{array}{ll}
-1 & 1 \\
-1 & 1
\end{array}\right], \\
\mathbf{B}_{m}(\mathbf{x})=\frac{1}{C_{m} \rho_{m}} \operatorname{diag}\left(\left[\frac{1}{A_{m 2} l_{13}} \frac{1}{A_{m 4}\left(l_{15}-l_{13}\right)}\right]^{T}\right) .
\end{gathered}
$$

3.3. Algebraic Equations of the Primary Side. According to the nodalization scheme illustrated in Figure 4, the primary side is also divided into two sections. Since the primary coolant is single-phase helium whose flowing velocity is much faster than that of the two-phase flow inside the secondary side, the algebraic equations are used to give the energy and temperature relationship of the first side. 
From the conservation law of energy, it is clear that

$$
\begin{aligned}
& Q_{p 2}=C_{p} G_{p}\left(T_{p 3}-T_{p 1}\right), \\
& Q_{p 4}=C_{p} G_{p}\left(T_{p 5}-T_{p 3}\right),
\end{aligned}
$$

where $G_{p}$ is the helium flowrate, $C_{p}$ is the helium specific heat, and $T_{p i}$ is the helium temperature at point $i(i=$ $1, \ldots, 5)$.

Moreover, from the energy balance relationship between the primary and secondary side, it is clear to see that

$$
\begin{aligned}
& Q_{p 2}=K_{p 2} l_{13}\left(T_{p 2}-T_{m 2}\right), \\
& Q_{p 4}=K_{p 4} l_{35}\left(T_{p 4}-T_{m 4}\right), \\
& Q_{s 2}=K_{s 2} l_{13}\left(T_{m 2}-T_{s 2}\right), \\
& Q_{s 4}=K_{s 4} l_{35}\left(T_{m 4}-T_{s 4}\right),
\end{aligned}
$$

where $T_{s i}$ is the temperature of the two-phase flow inside the secondary side at point $i(i=1, \ldots, 5), K_{p 2}$ and $K_{p 4}$ are the heat transfer coefficients between the primary side and tubewall of the subcooled and boiling sections, respectively, and $K_{s 2}$ and $K_{s 4}$ are, respectively, the heat transfer coefficients between the tube-wall and secondary side of the subcooled and boiling sections.

Moreover, assume that the helium temperature distribution along the $x$-axis defined in Figure 4 is linear, and then we can easy obtain that

$$
\begin{gathered}
T_{p 1}=2 T_{p 2}-T_{p 3}, \\
T_{p 3}=\frac{T_{p 2} l_{35}+T_{p 4} l_{13}}{l_{15}} .
\end{gathered}
$$

Based on (32)-(34), the algebraic equation for describing the operation characteristics of the primary side can be written as

$$
\mathbf{A}_{p}\left(\mathbf{x}_{s}\right) \mathbf{x}_{p}=\mathbf{b}_{p}\left(\mathbf{x}_{m}, \mathbf{x}_{p}\right)
$$

where

$$
\begin{gathered}
\mathbf{x}_{p}=\left[\begin{array}{llll}
T_{p 1} & T_{p 2} & T_{p 3} & T_{p 4}
\end{array}\right]^{T}, \\
\mathbf{A}_{p}\left(\mathbf{x}_{m}\right)=\left[\begin{array}{cccc}
1 & -2 & 1 & 0 \\
0 & l_{35} & -l_{15} & l_{13} \\
-C_{p} G_{p} & -K_{p 2} l_{13} & C_{p} G_{p} & 0 \\
0 & 0 & -C_{p} G_{p} & -K_{p 4} l_{35}
\end{array}\right], \quad \text { (37) } \\
\mathbf{b}_{p}\left(\mathbf{x}_{m}, \mathbf{x}_{p}\right)=\left[\begin{array}{lllll}
0 & 0 & -K_{p 2} l_{13} T_{m 2} & -K_{p 4} l_{35} T_{m 4}-C_{p} G_{p} T_{p 5}
\end{array}\right]^{T} .
\end{gathered}
$$

3.4. Differential-Algebraic State-Space Model. Based upon the above analysis and derivation, define the state-vector $\mathbf{x}$ and input-vector $\mathbf{u}$ as

$$
\begin{gathered}
\mathbf{x}=\left[\begin{array}{lll}
\mathbf{x}_{s}^{T} & \mathbf{x}_{m}^{T} & \mathbf{x}_{p}^{T}
\end{array}\right]^{T}, \\
\mathbf{u}=\left[\begin{array}{llll}
G_{s 1} & h_{f w} & G_{p} & G_{p} T_{p 5}
\end{array}\right]^{T},
\end{gathered}
$$

where $\mathbf{x}_{s}, \mathbf{x}_{m}$, and $\mathbf{x}_{p}$ are given by (20), (28), and (36), respectively. Then, the differential-algebraic model of the OTSG for MHTGR-based multimodular nuclear plants can be summarized as

$$
\mathbf{E}(\mathbf{x}) \dot{\mathbf{x}}=\mathbf{f}(\mathbf{x})+\mathbf{G}(\mathbf{x}) \mathbf{u},
$$

where

$$
\begin{aligned}
& \mathbf{E}(\mathbf{x})=\left[\begin{array}{cc}
\Xi(\mathbf{x}) & \mathbf{O}_{6 \times 4} \\
\mathbf{O}_{4 \times 6} & \mathbf{O}_{4}
\end{array}\right], \\
& \mathbf{G}(\mathbf{x})=\left[\begin{array}{lll}
\mathbf{G}_{1}^{T}(\mathbf{x}) & \mathbf{O}_{4} & \mathbf{G}_{2}^{T}(\mathbf{x})
\end{array}\right]^{T}, \\
& \mathbf{f}(\mathbf{x})=\left[\begin{array}{c}
G_{s 3}\left(2 A_{s 3}\right)^{-1}\left(h_{s 1}-h_{s 3}\right)+K_{s 2} l_{13} A_{s 2}^{-1}\left(T_{m 2}-T_{s 2}\right) \\
A_{s 4}^{-1}\left[G_{s 4}\left(h_{s 3}-h_{s 5}\right)+K_{s 4}\left(l_{15}-l_{13}\right)\left(T_{m 4}-T_{s 4}\right)\right] \\
-h_{s 1} \tau_{H}^{-1} \\
-G_{s 3} \tau_{G}^{-1} \\
\left(C_{m} \rho_{m} A_{m 2}\right)^{-1}\left[K_{p 2} T_{p 2}+K_{s 2} T_{s 2}-\left(K_{p 2}+K_{s 2}\right) T_{m 2}\right] \\
\left(C_{m} \rho_{m} A_{m 4}\right)^{-1}\left[K_{p 4} T_{p 4}+K_{s 4} T_{s 4}-\left(K_{p 4}+K_{s 4}\right) T_{m 4}\right] \\
2 T_{p 2}-\left(T_{p 1}+T_{p 3}\right) \\
l_{15} T_{p 3}-\left(l_{15}-l_{13}\right) T_{p 2}-l_{13} T_{p 4} \\
K_{p 2} l_{13}\left(T_{p 2}-T_{m 2}\right) \\
K_{p 4}\left(l_{15}-l_{13}\right)\left(T_{p 4}-T_{m 4}\right)
\end{array}\right],
\end{aligned}
$$




$$
\begin{gathered}
\mathbf{\Xi}(\mathbf{x})=\left[\begin{array}{ccccccc}
E_{s 11}\left(\mathbf{x}_{m}\right) & 0 & \frac{\rho_{s 2} l_{13}}{2} & E_{s 14}\left(\mathbf{x}_{m}\right) & 0 & 0 \\
E_{s 21}\left(\mathbf{x}_{m}\right) & \frac{\rho_{s 4} l_{35}}{2} & 0 & E_{s 24}\left(\mathbf{x}_{m}\right) & 0 & 0 \\
0 & 0 & \tau_{H} & 0 & 0 & 0 \\
0 & 0 & 0 & \tau_{G} & 0 & 0 \\
\left(T_{m 2}-T_{m 4}\right) l_{15}^{-1} & 0 & 0 & 0 & 1 & 0 \\
\left(T_{m 2}-T_{m 4}\right) l_{15}^{-1} & 0 & 0 & 0 & 0 & 1
\end{array}\right], \\
\mathbf{G}_{1}(\mathbf{x})=\left[\begin{array}{ccccc}
\left(2 A_{s 1}\right)^{-1}\left(h_{s 1}-h_{s 3}\right) & 0 & 0 & 0 \\
0 & 0 & 0 & 0 \\
0 & \tau_{H}^{-1} & 0 & 0 \\
\tau_{G}^{-1} & 0 & 0 & 0
\end{array}\right], \\
\mathbf{G}_{2}(\mathbf{x})=\left[\begin{array}{ccccc}
0 & 0 & C_{p}\left(T_{p 1}-T_{p 3}\right) & 0 \\
0 & 0 & C_{p} T_{p 3} & -C_{p}
\end{array}\right] .
\end{gathered}
$$

In the process of developing dynamic model (40), there is no assumption on the outlet steam to be superheated, which means that this model can describe the dynamic behavior of the OTSG in the case of generating saturate steam and also can also roughly describe the dynamics in the case of providing super-heated steam. Moreover, due to the simplicity of model (40), it can be used to design steam temperature controller for the OTSG.

\section{Numerical Simulation Results}

In order to verify the feasibility of differential-algebraic OTSG model (40), we applied it to simulate the dynamic behavior of the OTSG in the HTR-PM plant. The numerical simulation is done in MATLAB/ SIMULINK environment. The model parameters are given by physical and thermal design of this OTSG. In the following, both the steady and transient simulations are performed, and some necessary discussions are also given.

4.1. Steady Results. The main steady-state results at the operating power-levels of $100 \%, 90 \%, 75 \%, 50 \%$, and $30 \%$ reactor full power (RFP) with comparison to the designed values are given in Table 1 .

4.2. Transient Results. For verifying the feasibility of model (40) in describing the OTSG dynamic behavior, the transient results corresponding to the following three cases are given.

Case A: Step Decease in the Helium Flowrate at 75\% RFP. After the system operates at the steady state of $75 \%$ RFP for $2000 \mathrm{~s}$, a step decrease of $5 \mathrm{~kg} / \mathrm{s}$ in the primary helium flowrate is added to the system, and the corresponding transient responses of outlet steam temperature $T_{s 5}$, the length of the subcooed section $l_{13}$, the outlet steam quality $x_{M}$, and oulet cold helium temperature $T_{p 1}$ are shown in Figure 5. Here, steam quality $x_{M}$ is defined by

$$
x_{M}=\frac{h_{s 5}-h_{l}}{h_{g l}},
$$

where $h_{l}$ is specific enthalpy of saturated steam corresponding to outlet steam pressure $P_{s 5}$, and $h_{g l}$ is the latent heat of vaporization corresponding to $P_{s 5}$. If $x_{M}>1$, then the outlet steam is superheated. If $x_{M} \leq 1$, then the outlet steam is saturate.

Case B: Step Decrease in the Feedwater Flowrate at 75\% RFP. The system operates at the steady state of $75 \%$ RFP for $2000 \mathrm{~s}$, and then a step decrease in the feed-water flowrate with the value of $5 \mathrm{~kg} / \mathrm{s}$ is added. The transient responses of outlet steam temperature $T_{s 5}$, length of the subcooed section $l_{13}$, outlet steam quality $x_{M}$, and outlet cold helium temperature $T_{p 1}$ are all illustrated in Figure 6.

Case C: Step Increase in the Feedwater Flowrate at 30\% RFP. The system operates at the steady state of $30 \%$ RFP for $2000 \mathrm{~s}$, and then a step increase in the feed-water flowrate with the value of $25 \mathrm{~kg} / \mathrm{s}$ is added. The transient responses of outlet steam temperature $T_{s 5}$, length of the subcooed section $l_{13}$, outlet steam quality $x_{M}$, and outlet cold helium temperature $T_{p 1}$ are all illustrated in Figure 7. This case is utilized to show that model (40) can simulate the OTSG dynamics when saturate steam is generated.

4.3. Discussions. By comparing the simulated and designed values given in Table 1, we can clearly see that the maximal relative error is no more than $2 \%$, which shows that differential-algebraic model (40) has a high steady precision.

In case $\mathrm{A}$, since the inlet hot helium temperature is constant, the step decrease in the helium flowrate results in 
TABLE 1: Comparison of the steady simulation results and designed data.

\begin{tabular}{|c|c|c|c|c|c|}
\hline Power-level/RFP & $100 \%$ & $90 \%$ & $75 \%$ & $50 \%$ & $30 \%$ \\
\hline Helium flowrate $G_{p} /(\mathrm{kg} / \mathrm{s})$ & 96.26 & 83.95 & 72.58 & 51.3 & 33.44 \\
\hline Feedwater flowrate $G_{s 1} /(\mathrm{kg} / \mathrm{s})$ & 93.25 & 84.24 & 70.75 & 48.76 & 30.93 \\
\hline Hot helium temperature $T_{p 5}{ }^{\circ} \mathrm{C}$ & 750.0 & 743.5 & 733.75 & 717.5 & 704.5 \\
\hline Feedwater temperature $T_{\mathrm{fw}} /{ }^{\circ} \mathrm{C}$ & 205.2 & 199.1 & 191.1 & 175.1 & 157.1 \\
\hline Designed outlet steam temperature $T_{s 50} /{ }^{\circ} \mathrm{C}$ & 571.0 & 571.0 & 571.0 & 571.0 & 571.0 \\
\hline Simulated outlet steam temperature $T_{s 5} /{ }^{\circ} \mathrm{C}$ & 571.0 & 571.0 & 571.0 & 571.0 & 571.0 \\
\hline Relative error of steam temperature/\% & 0.0 & 0.0 & 0.0 & 0.0 & 0.0 \\
\hline Designed cold helium temperature $T_{p 1} /{ }^{\circ} \mathrm{C}$ & 243.0 & 237.2 & 228.5 & 214.0 & 202.4 \\
\hline Simulated cold helium temperature $T_{p 1} /{ }^{\circ} \mathrm{C}$ & 242.5 & 236.5 & 229.4 & 215.2 & 200.0 \\
\hline Relative error of cold helium temperature/\% & 0.20 & 0.30 & 0.39 & 0.56 & 1.19 \\
\hline
\end{tabular}
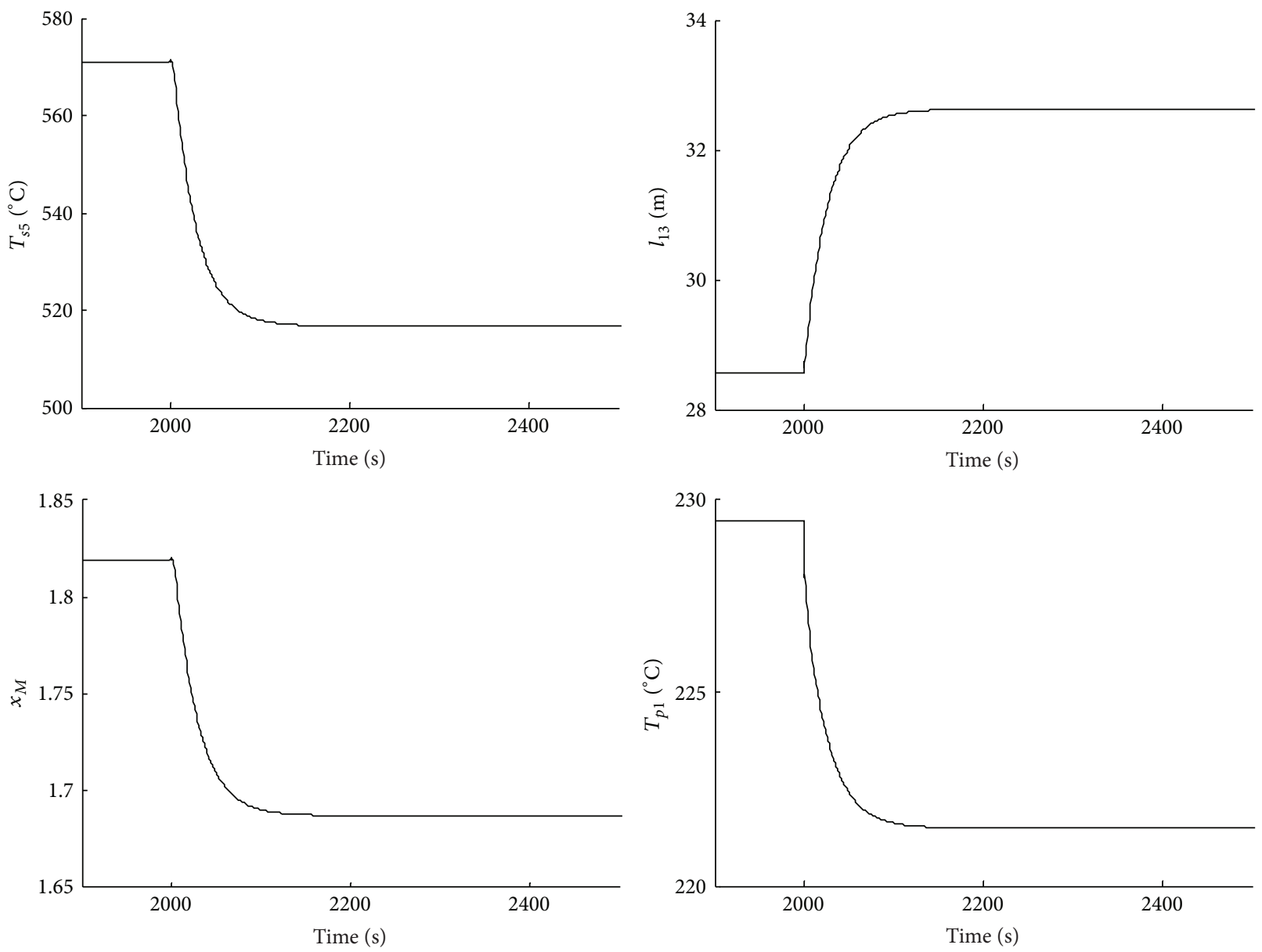

Figure 5: Simulation results in case A.

the decrease of the heat transferred from the primary to the secondary side, which then induce the decreases in the outlet steam temperature, steam quality and length of the boiling section. Moreover, thermal power transferred from the primary to the secondary sides is also reduced, which further causes the decrease of the primary average helium temperature. Since the inlet hot temperature is not changed, the decrease in average helium temperature certainly results in the decrease of outlet cold helium temperature. From
Figure 5, the above physical analysis well copes with the numerical results.

In the case of feedwater flowrate decrease at $75 \%$ RFP, since both the inlet helium temperature and primary helium flowrate remain constant when the step decrease in the feedwater flowrate occurs, the thermal power transferred from the primary helium flow to the tube-wall is not changed at the beginning. Then, the decrease in the feedwater flowrate must lead to the increases of the outlet steam temperature and 

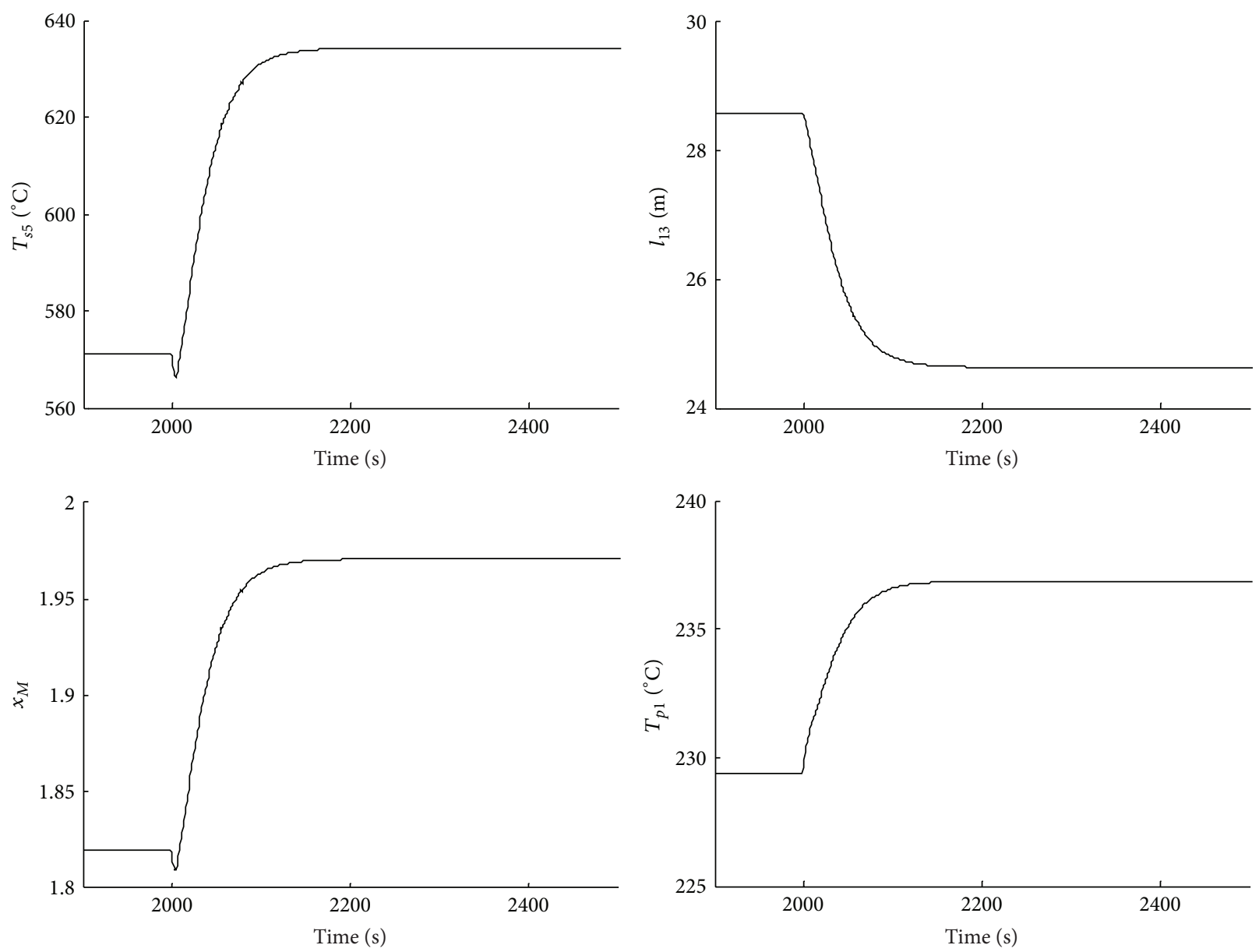

FIGURE 6: Simulation results in case B.

steam quality and lengthening of the boiling section. Since the specific enthalpy of the feedwater is constant, the increase of the steam temperature reduces the temperature difference between the two sides of the OTSG, which leads to the decrease of the thermal power transferred from the primary to the secondary sides, and certainly further results in the increase of the temperature of the primary outlet helium flow. From Figure 6, the numerical phenomenon is in accordance with the above physical analysis in this case.

In case $\mathrm{C}$, after the occurrence of the large step increase in the feedwater flowrate, the outlet steam temperature is quickly and largely decreased since the thermal power transferred from the primary side is nearly not changed at the initial stage. The decrease in the steam temperature is certainly equivalent to the decreases of the boiling section length and steam quality, and results in a larger temperature difference between the two sides of the OTSG. This difference certainly enlarges thermal power transferred to the secondary side, and then results in the temperature decrease of the primary outlet cold helium. The above analysis well accords with the numerical results in Figure 7. Moreover, from Figure 7, the step increase of the feedwater flowrate is so large that the OTSG outlet steam becomes saturated quickly, which means that differential-algebraic model (40) can be used for transient simulation in case of generating saturate steam.
Finally, from the above discussion, we can easily see that the steady precision of dynamic model (40) is very high, and the transient responses of this model can well cope with the physical trend of the OTSG. Moreover, this model can well describe the dynamic behavior of the OTSG in case of generating saturate steam. Actually, this model has already been adopted to develop the real-time software for the operation and control features of the HTR-PM plant, as shown in Figure 8 [16].

\section{Conclusions}

Due to the inherent safety feature of the SMR, SMR-based nuclear plants are an important developing trend of the nuclear energy systems. Based upon the multimodular operation strategy, SMRs can be used to build nuclear plants with any desired power rating and inherent safety. The OTSG is key equipment of any SMR-based multimodular nuclear plants, and developing the dynamic model for the OTSG is very meaningful to study the dynamic behavior of the multimodular nuclear plants. In this paper, based on the conservation laws of mass, energy, and momentum, a differential-algebraic model for the OTSG of those MHTGRbased multimodular nuclear plants is presented. This model can describe the dynamic behavior of the OTSG in both 

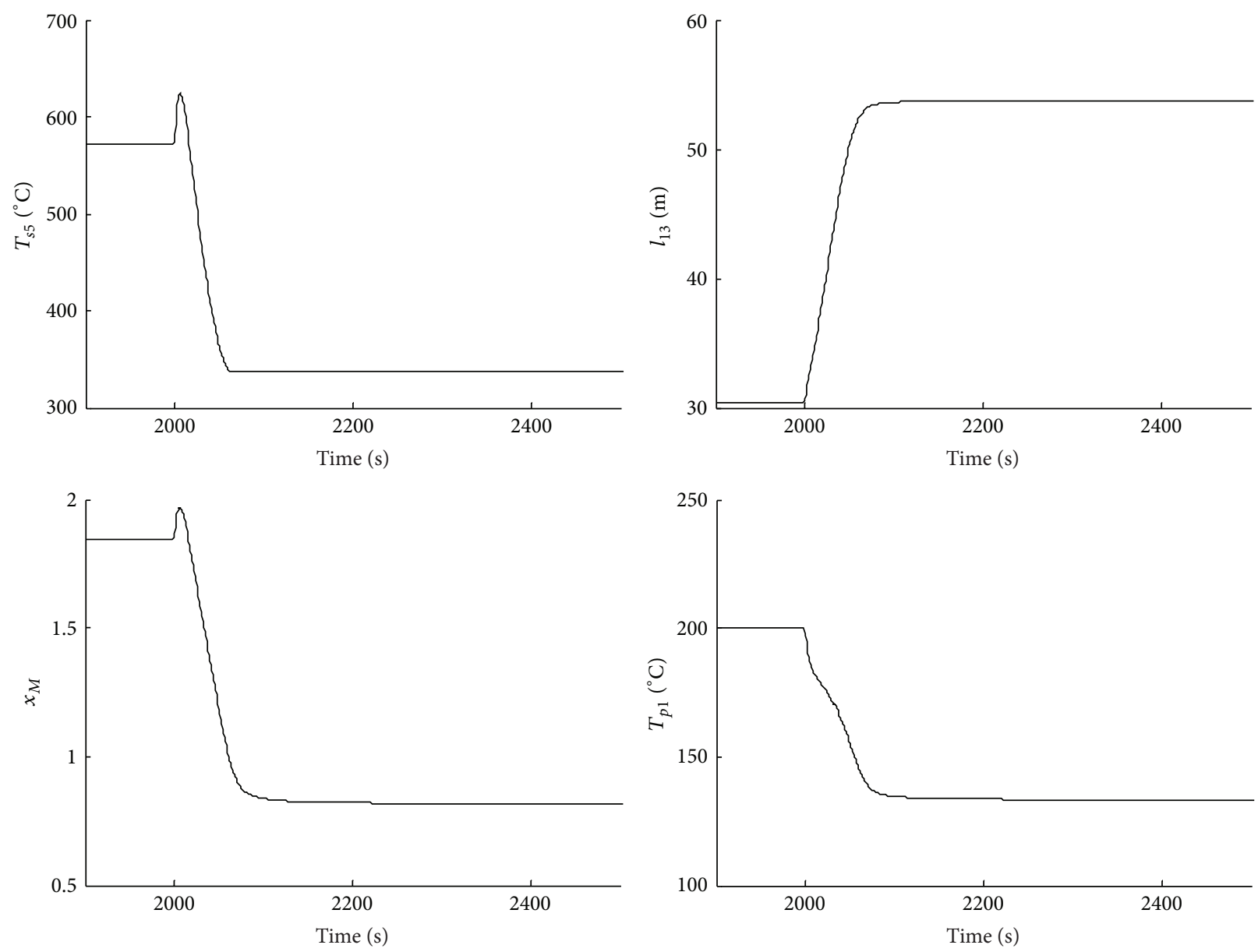

Figure 7: Simulation results in case C.

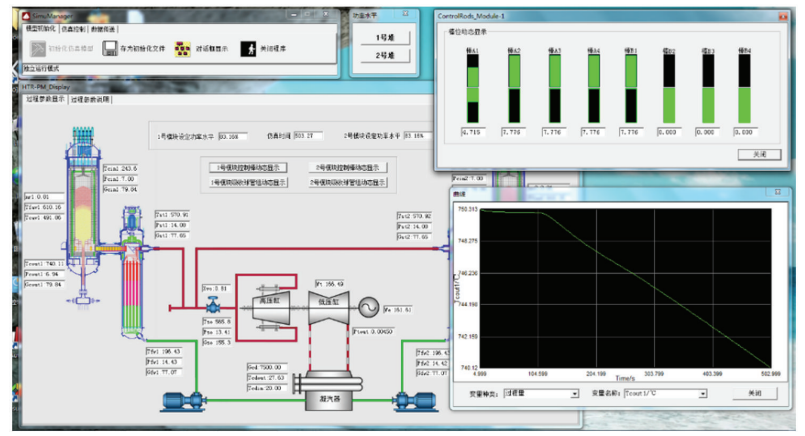

FIGURE 8: Real-time simulation software for the HTR-PM operation by using model (40).

the cases of providing superheated steam and generating saturated steam. Moreover, since the relative simplicity of this model, it can also be applied to design steam temperature control laws for the OTSGs. Numerical simulations results show that this model has a satisfactory steady precision, and its transient responses well accord with the thermodynamic behavior of the OTSG. This model has already been applied to develop a real-time simulation software for the operation and control strategy design and verification of the HTR-PM plant. In the future, more simulation results of the closedloop dynamic responses will be given by coupling this new OTSG model with steam temperature control laws.

\section{Conflict of Interests}

The author declares that there is no conflict of interests regarding the publication of this paper.

\section{References}

[1] D. T. Ingersoll, "Deliberately small reactors and the second nuclear era," Progress in Nuclear Energy, vol. 51, no. 4-5, pp. 589603, 2009.

[2] J. Vujić, R. M. Bergmann, R. Škoda, and M. Miletić, "Small modular reactors: simpler, safer, cheaper?" Energy, vol. 45, no. 1, pp. 288-295, 2012.

[3] M. D. Carelli, L. E. Conway, L. Oriani et al., "The design and safety features of the IRIS reactor," Nuclear Engineering and Design, vol. 230, no. 1-3, pp. 151-167, 2004.

[4] IAEA, Status of Small and Medium Sized Reactor Designs, International Atomic Energy Agency, Vienna, Austria, 2012.

[5] G. H. Lohnert, "Technical design features and essential safetyrelated properties of the HTR-module," Nuclear Engineering and Design, vol. 121, no. 2, pp. 259-275, 1990. 
[6] Z. Wu, D. Lin, and D. Zhong, "The design features of the HTR10," Nuclear Engineering and Design, vol. 218, pp. 25-32, 2002.

[7] Z. Zhang and Y. Sun, "Economic potential of modular reactor nuclear power plants based on the Chinese HTR-PM project," Nuclear Engineering and Design, vol. 237, no. 23, pp. 2265-2274, 2007.

[8] Z. Zhang, Z. Wu, D. Wang et al., "Current status and technical description of Chinese $2 \times 250 \mathrm{MW}_{t h}$ HTR-PM demonstration plant," Nuclear Engineering and Design, vol. 239, no. 7, pp. 12121219, 2009.

[9] K. K. Kim and J. A. Bernard, "Considerations in the control of PWR-type multimodular reactor plants," IEEE Transactions on Nuclear Science, vol. 41, no. 6, pp. 2686-2697, 1994.

[10] S. R. P. Perillo, B. R. Upadhyaya, and F. Li, "Control and instrumentation strategies for multi-modular integral nuclear reactor systems," IEEE Transactions on Nuclear Science, vol. 58, no. 5, pp. 2442-2451, 2011.

[11] A. Ray, "Dynamic modelling of once-through subcritical steam generator for solar applications," Applied Mathematical Modelling, vol. 4, no. 6, pp. 417-423, 1980.

[12] A. Ray, "Nonlinear dynamic model of a solar steam generator," Solar Energy, vol. 26, no. 4, pp. 297-306, 1981.

[13] C. P. Tzanos, "Movable boundary model for once-through steam generator analysis," Nuclear Technology, vol. 82, no. 1, pp. 5-17, 1988.

[14] M. A. Abdalla, "A four-region, moving-boundary model of a once-through, helical-coil steam generator," Annals of Nuclear Energy, vol. 21, no. 9, pp. 541-562, 1994.

[15] H. Li, X. Huang, and L. Zhang, "A lumped parameter dynamic model of the helical coiled once-through steam generator with movable boundaries," Nuclear Engineering and Design, vol. 238, no. 7, pp. 1657-1663, 2008.

[16] Z. Dong and X. Huang, "Real-time simulation platform for the design and verification of the operation strategy of the HTR-PM," in Proceedings of the 21st International Conference on Nuclear Engineering (ICONE '13), Chengdu, China, August 2013. 


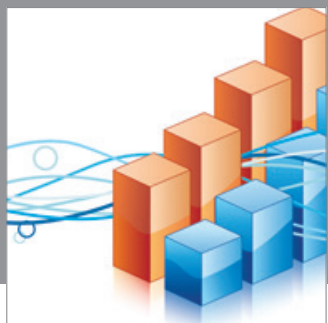

Advances in

Operations Research

mansans

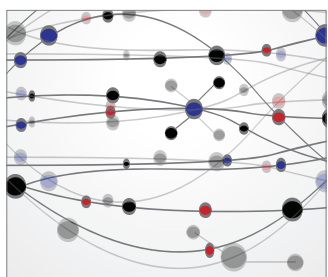

The Scientific World Journal
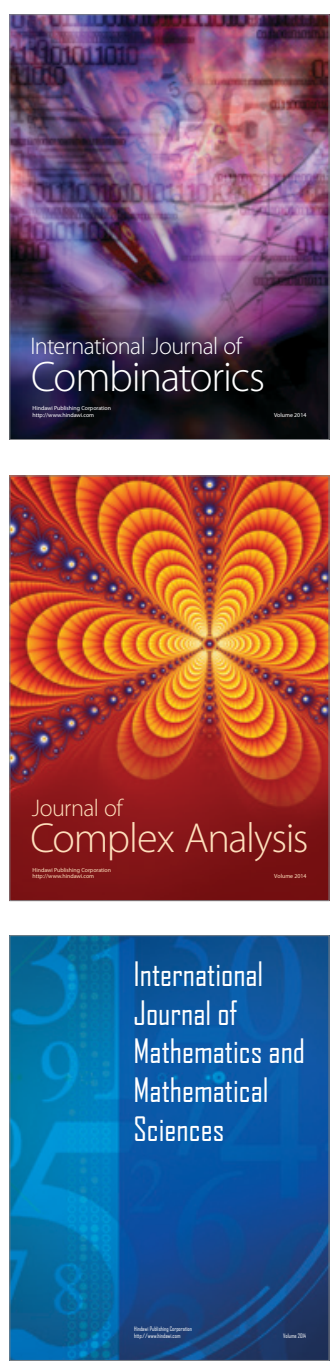
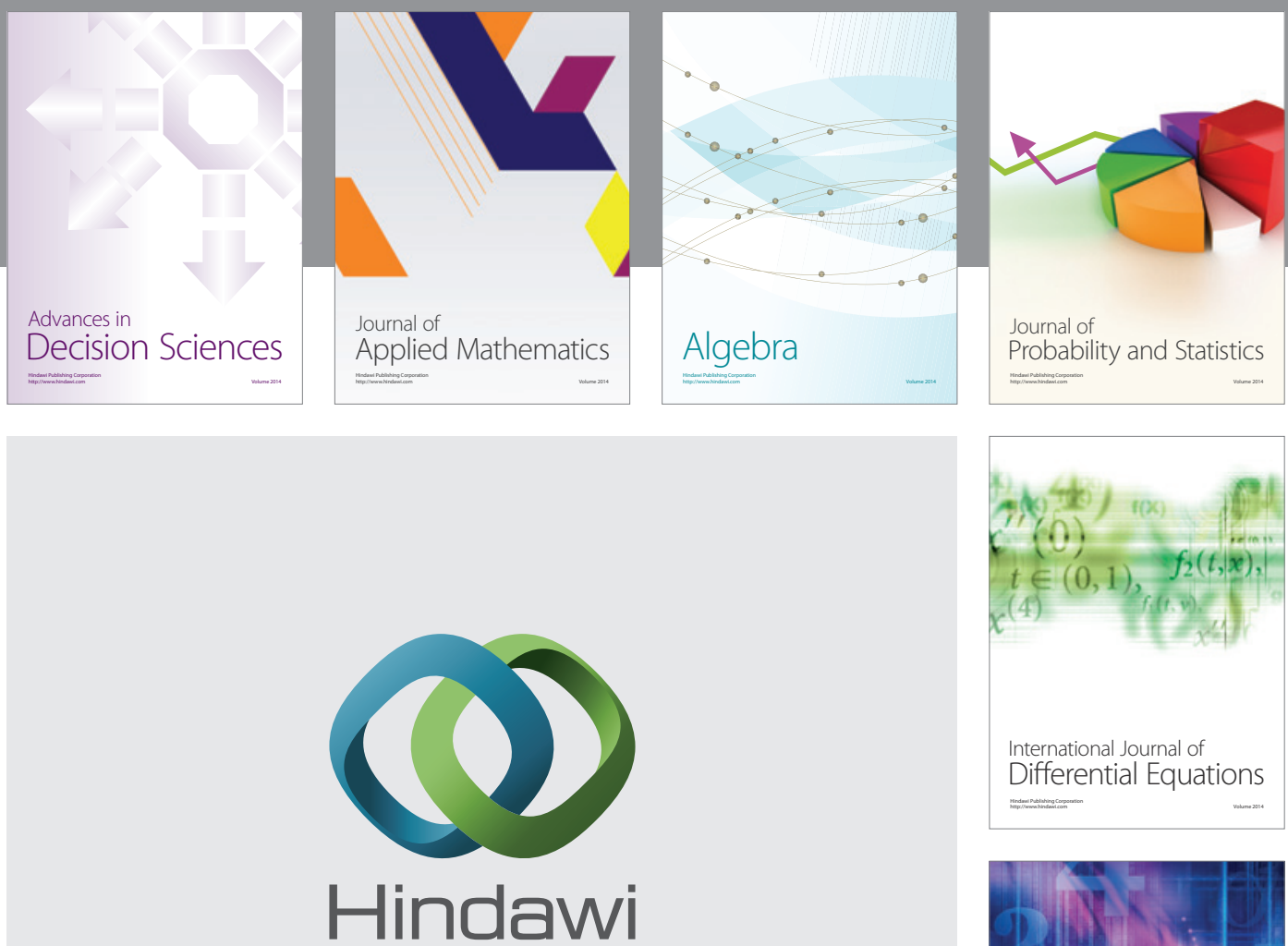

Submit your manuscripts at http://www.hindawi.com
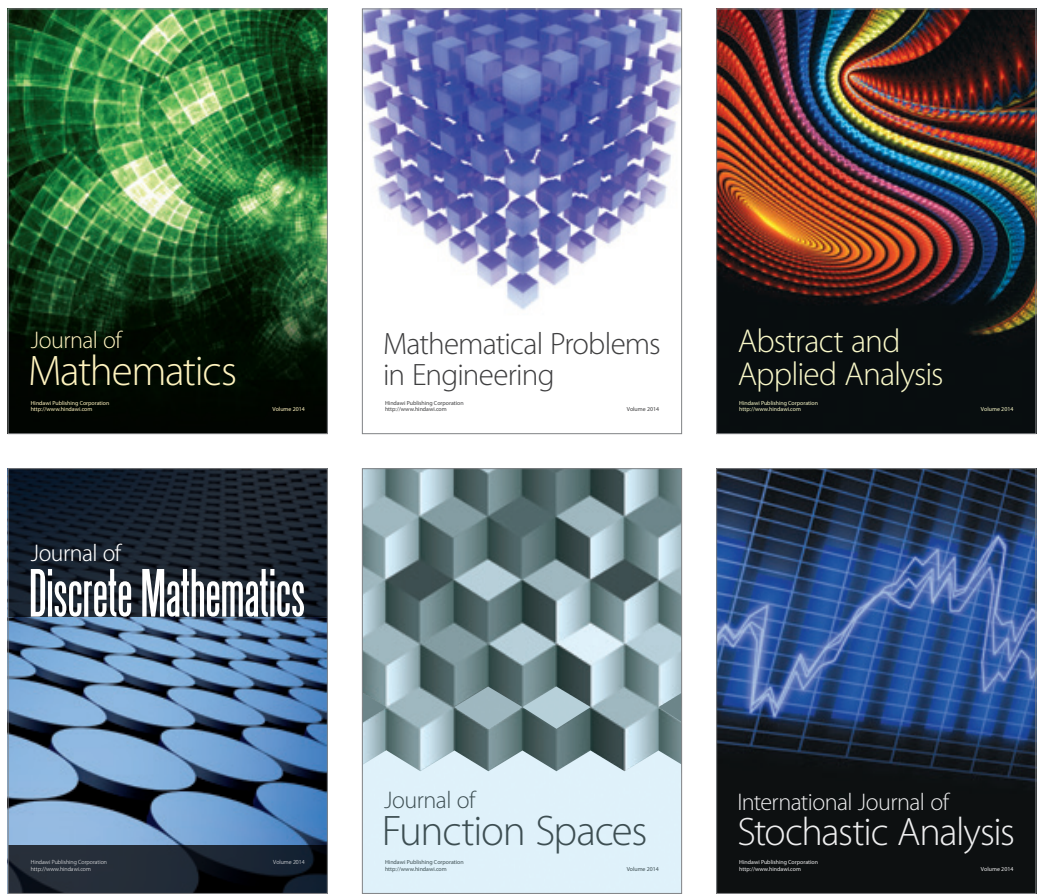

Journal of

Function Spaces

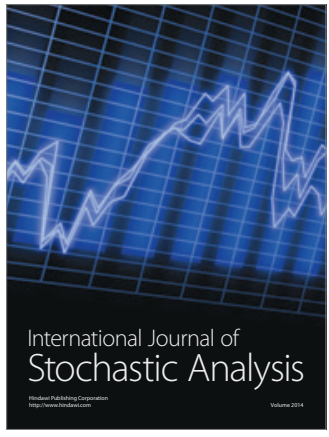

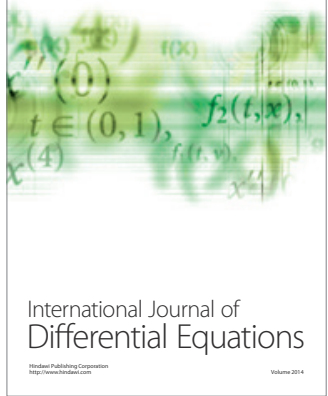
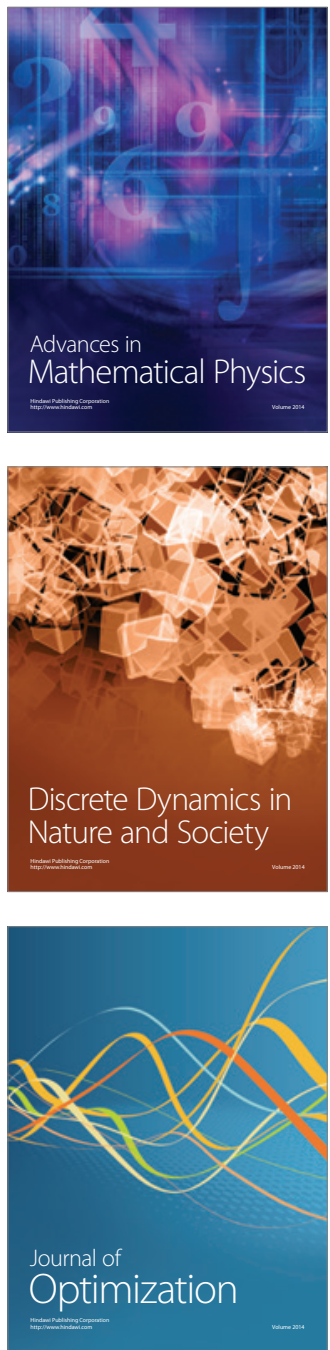